\title{
Prediction on Deflection of Box-Core Sandwich Panels in Weak Direction
}

\author{
CUI Mingjuan*
}

\author{
School of Civil Engineering \& Mechanics, Huazhong University of Science \& Technology, Luoyu Road 1037\#, Hong- \\ shan District, Wuhan, Hubei Province, PR China 430074
}

\begin{abstract}
A box-core sandwich panel is consisted of top and bottom facing plates and a core of box-shaped stiffeners connected to facing plates. According to the assumption that shear forces at the mid-height of box-core stiffeners are equal, a typical segment is studied, and the relative displacement at two ends of the typical segment is obtained by using unit load method. Therefore, a theoretical equation for calculating the deflection at the mid-span of a box-core sandwich beam is presented. To verify the accuracy of the equation, finite element software ABAQUS is adopted to carry out a parametric study to investigate the validity range. By comparing the theoretical and numerical results, the accuracy of the equation is verified.
\end{abstract}

Keywords: Bending behavior, box-core sandwich beam, finite element analysis, theoretical equation.

\section{INTRODUCTION}

A sandwich panel includes two facing plates and a series of core stiffeners connected to the facing plates by rivet or laser weld. Due to its high strength and light weight, sandwich panel has been widely used in many fields, especially in constructional industries. For a sandwich panel, compared to other forms of constructional sections, its section has much more space which can be used as an effective sound and heat insulation structure. Meanwhile, sandwich panel also has better energy absorption and dissipation capacities, which can effectively decrease tremendous energy caused by higher speed movement, as well as absorb enormous knock wave generated by explosion. Therefore, sandwich panel can be applied in variety of transportation tools, such as airplane, ship, high-speed train and so on.

Different materials can be used to form sandwich panel, such as metal sandwich panel [1], composite sandwich panel [2], concrete sandwich panel [3], and so forth. In addition, different core stiffeners can construct various forms of sandwich panels: X-core sandwich panel, Z-core sandwich panel, C-core sandwich panel, box-core sandwich panel and so on. In the past decades, the study of mechanical essence and structural mechanics behavior of the sandwich panel has been becoming very important in relative research fields. Libove and Hubka [4] obtained several elastic constants of sandwich panel with continuous corrugated core. Further study of sandwich panel was carried out by William [5]. Because Libove and Hubka's theory is valid only if the cross section of the core stiffeners is symmetrical about a vertical plane, therefore, Fung, Tan and Lok [6] studied the shear stiffness $\left(D_{Q y}\right)$ of C-core sandwich panels. Fung and Tan [7]

*Address correspondence to this author at the School of Civil Engineering \& Mechanics, Huazhong University of Science \& Technology, Luoyu Road 1037\#, Hongshan District, Wuhan, Hubei Province, PR China 430074;

Tel: +86-27-87557024; E-mail: Cuimingjuan1107@163.com also studied the shear stiffness $\left(D_{Q y}\right)$ of Z-core sandwich panel. They derived the equation for calculating shear stiffness, and verified the accuracy of the equation from experimental results. Wang et al. [8] analyzed the behavior of a sandwich panel with pyramidal truss cores, when subjecting to dynamic loads, by using Reissner sandwich panel theory. To simplify the study of sandwich panel, many theories and models are presented. However, some factors affecting the mechanical behavior of sandwich panel are ignored [9].

It can be found that most of the above researches focus on the study of shear stiffness, bending stiffness under static loading, or the behavior of sandwich panel subjected to dynamic loads. Hence, it is necessary to carry out some studies on bending behavior of box-core sandwich panel, and to derive the equation to calculate the deflection of box-core sandwich panel, by considering the effect of contact force between the facing plate and core stiffeners.

\section{THEORETICAL ANALYSIS}

\section{Typical Segment in a Sandwich Beam}

For a box-core sandwich panel, there are two directions, i.e. strong direction and weak direction. In the strong direction perpendicular to the cross section of box-core stiffeners ( $X$-direction), very small deflection will occur due to high bending and shear stiffness. In the weak direction parallel to the cross section of box-core stiffeners ( $Y$-direction), deflection may be much bigger because of weak shear capacity. A box-core sandwich panel is shown in Fig. (1).

As can be seen in Fig. (1), the box-cores are placed only in one direction with intervals. The sandwich panel is simply supported at two ends in the weak direction, and subjected to uniform loading. Therefore, a typical segment with unit width can be isolated from a sandwich panel for analysis and the corresponding internal forces are presented in Fig. (2). The symbols $b, h, S$ denote the length of flange of a box-core 


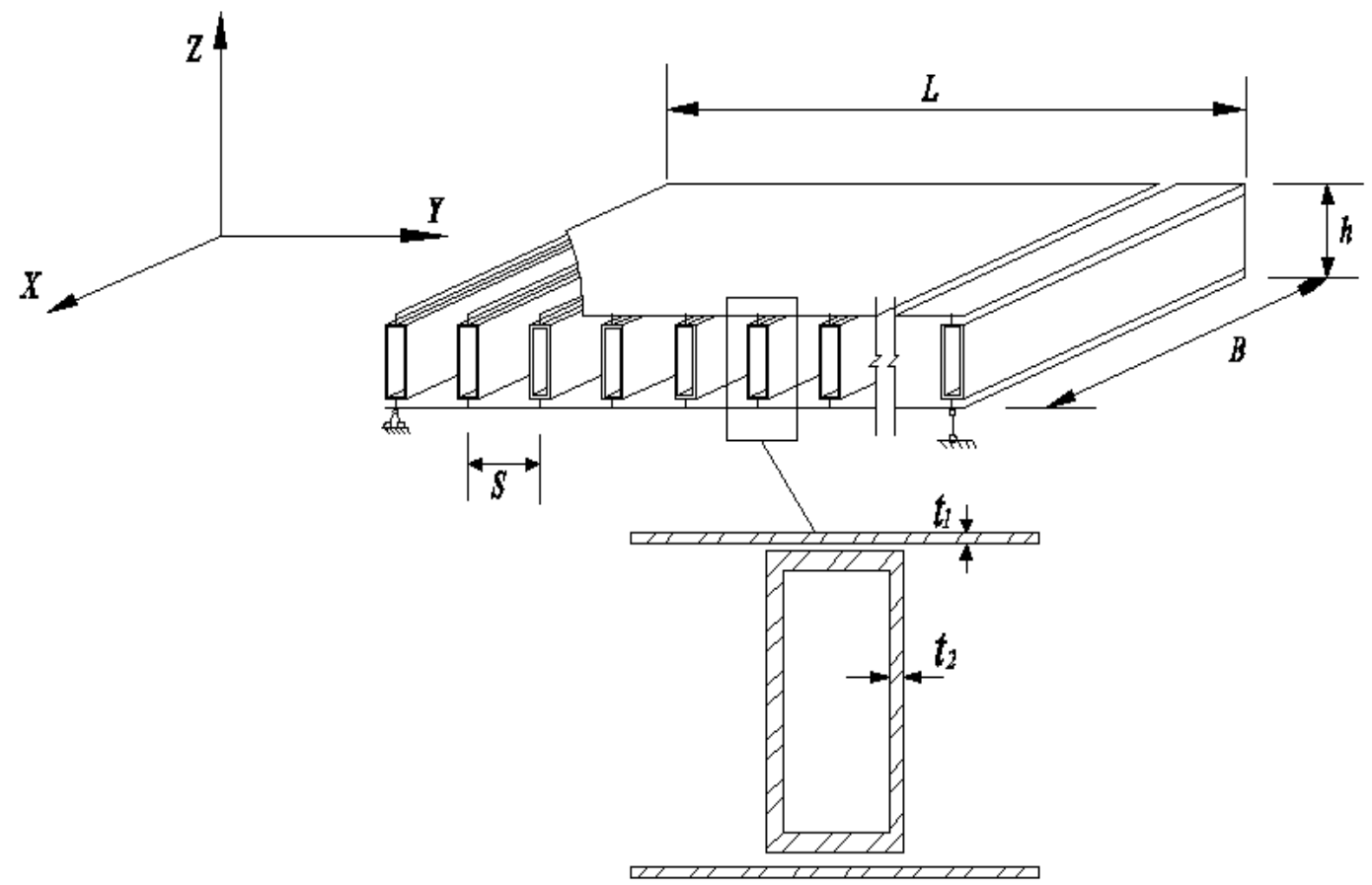

Fig. (1). Box-core sandwich panel.

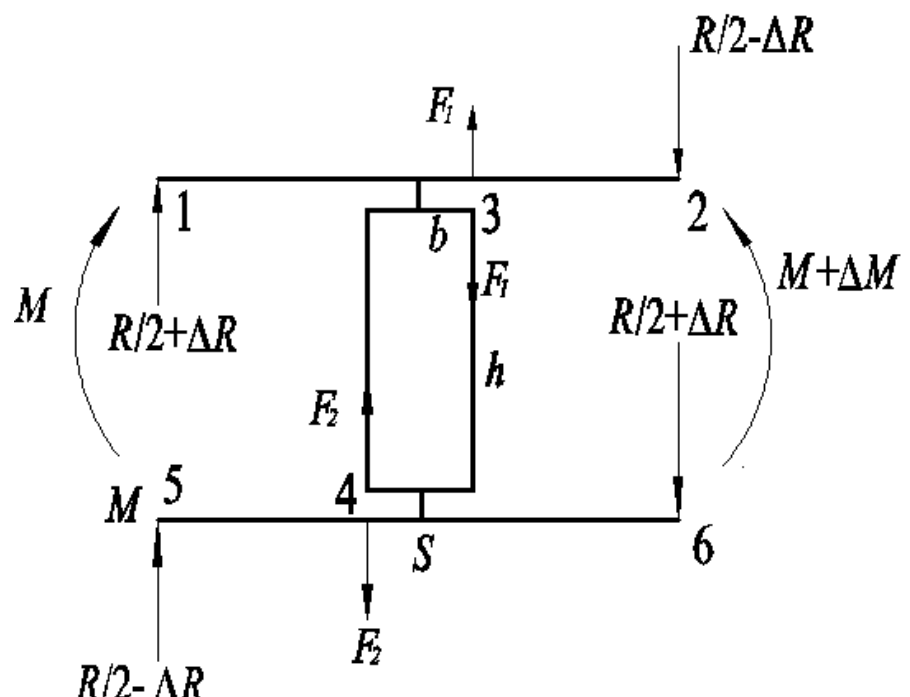

Fig. (2). Typical segment.

stiffener, the distance between the centerlines of the top and bottom facing plates, and the pitch of the box-core stiffeners, respectively. In $Y$ direction, bending moment $(M)$ varies in different locations. Therefore, let $M, M+\Delta M$ denote the bending moments at left and right ends of the typical segment, respectively, and similarly, $R / 2+\Delta R, R / 2-\Delta R$ denote the shear forces at left ends of the typical segment, respectively. As the box-cores are connected to the top and bottom facing plates with laser weld or screws, contact forces should be considered. Let $F_{1}, F_{2}$ be the contact forces between facing plate and box-core. $t_{1}$ and $t_{2}$ are used to denote the thickness of the facing plate and box-core, respectively.

According to Fig. (2), $L$ denotes the distance between point 1 and left end of sandwich panel, then $M$ and $M+\Delta M$ can be presented as follows
$M=R \cdot L$

$M+\Delta M=R(L+S)$

For brevity, bending moment $M$ and $M+\Delta M$ can be transformed into a couple of axial loads $(N, N+\Delta N)$ in facing plates and corresponding distance (as shown in Fig. 3). Therefore, $M$ and $M+\Delta M$ can be expressed as follows:

$M=N \cdot h$

$M+\Delta M=(N+\Delta N) h$

It should be noted that the thickness of the plates including facing plates and the box-cores are ingored during analysis. 


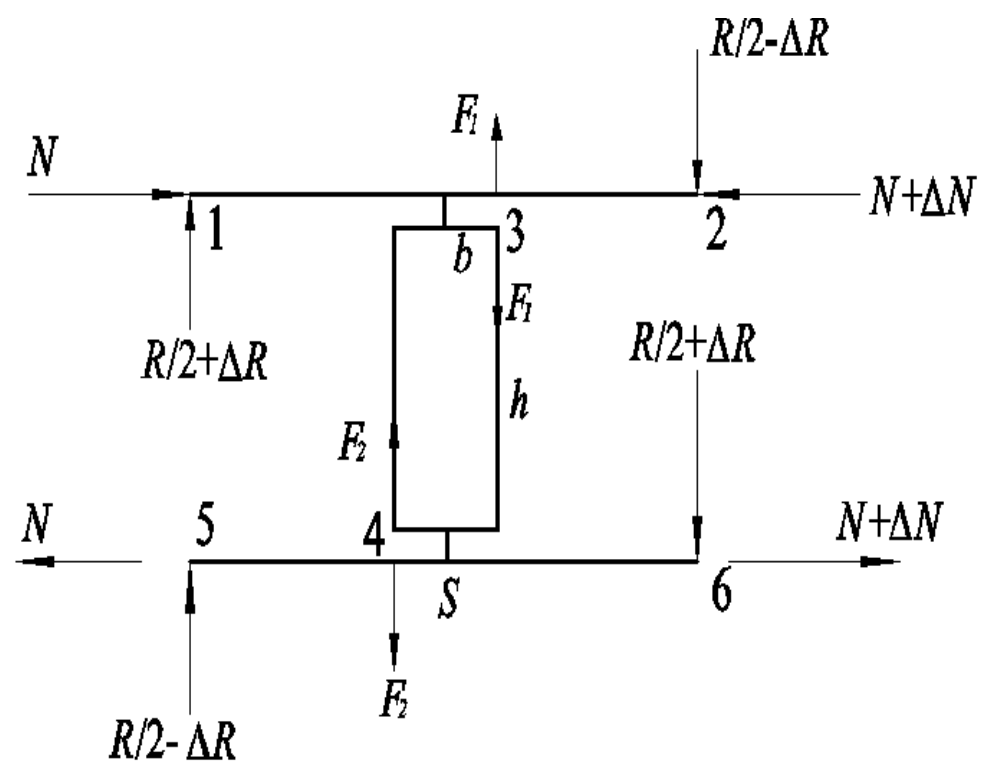

Fig. (3). The equivalent axial loads in typical segment.

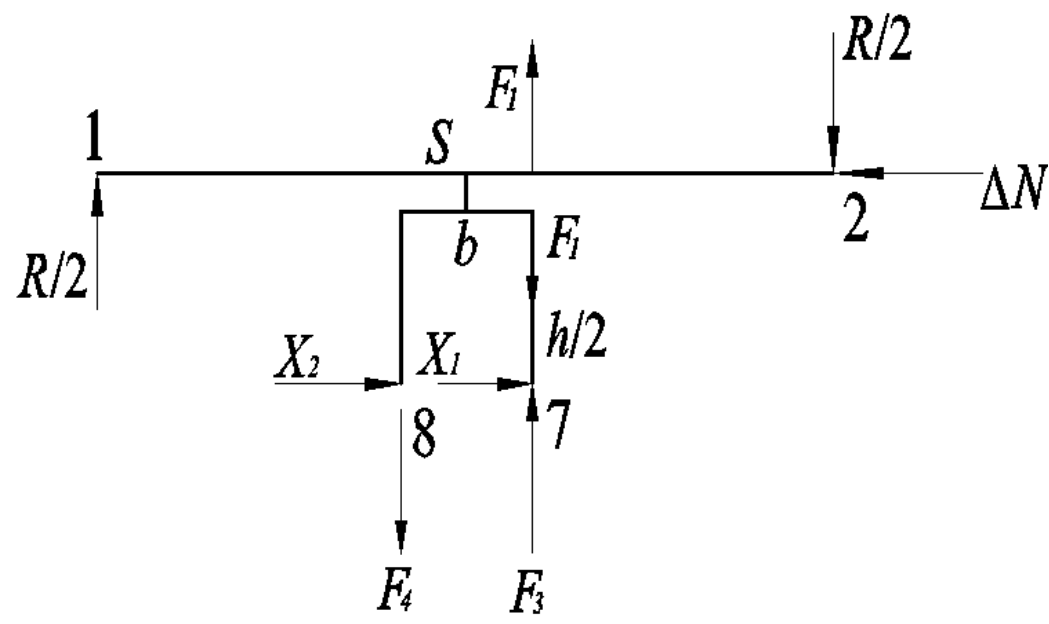

Fig. (4). Semi-structure of typical segment.

Hence, $\Delta N$ can be obtained from Eqs. (1) (4) as follow

$\Delta N=\frac{R \cdot S}{h}$

Due to symmetry of the typical segment, it is clear that the following equation is satisfied:

$\Delta R=0$

Similarly, the typical segment can be simplified into semi-structure to derive contact forces $F_{1}, F_{2}$ as shown in Fig. (4).

Shear forces $X_{1}$ and $X_{2}$ (in Fig. 4) can be directly determined by the following equation:

$X_{1}=X_{2}=\frac{\Delta N}{2}$

The internal forces $F_{3}$ and $F_{4}$ denote the axial loads of the webs of a box-core. According to the principle that the sum of all forces in the vertical direction of the typical segment is zero, $F_{3}$ and $F_{4}$ can be expressed as the following equation:
$F_{3}=F_{4}$

Similarly, the moment that all forces generated at point 8 is zero, and the equation can be determined as follow:

$\sum M_{8}=0$

Eq. (9) can produce the following results:

$F_{3}=F_{4}=\frac{R S-\Delta N \cdot h}{2 b}$

\section{Compatibility Conditions}

It is assumed that each segment of a box-core sandwich panel is similar to the adjacent one. This means the deformation of a typical segment with adjacent one is similar. Therefore, the compatibility conditions between typical segments are established. No relative vertical displacement is assumed to occur at contact point. $\Delta_{\mathrm{F}_{1}}$ and $\Delta_{\mathrm{F}_{1}}^{\prime}$ denote the displacements of facing plate and box-core at contact point, respectively: 


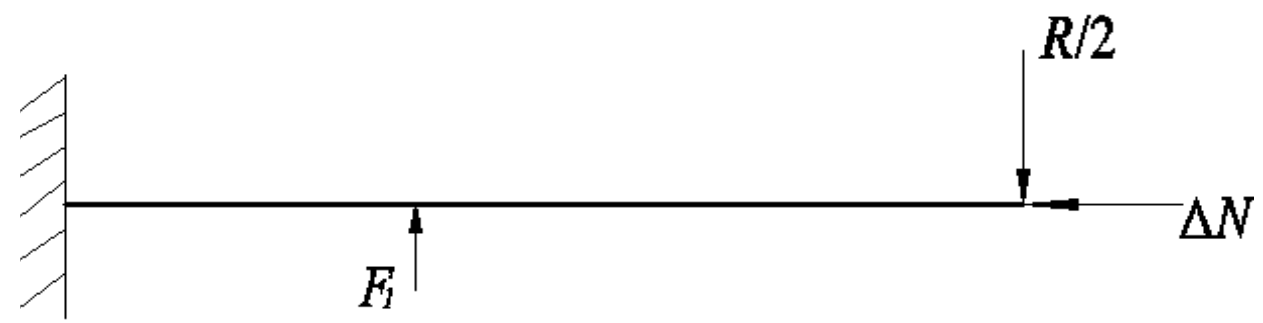

Fig. (5). Simplified semi-structure of top facing plate.

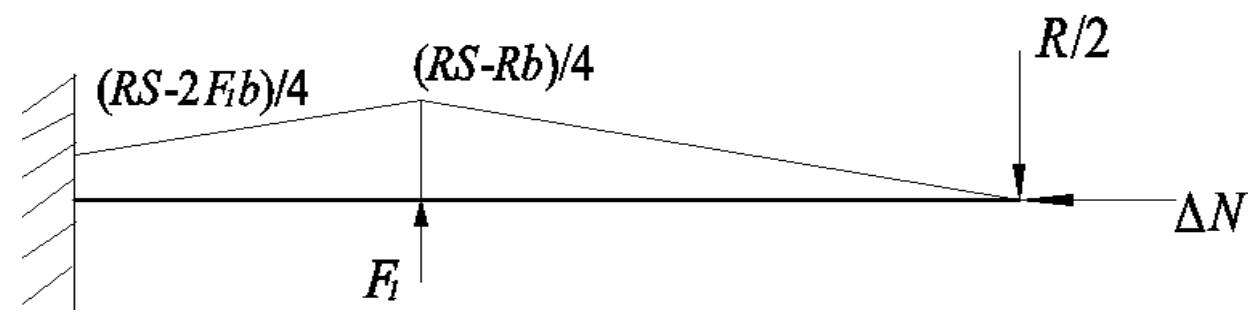

Fig. (6). Bending moment diagram of semi-structure of top facing plate.

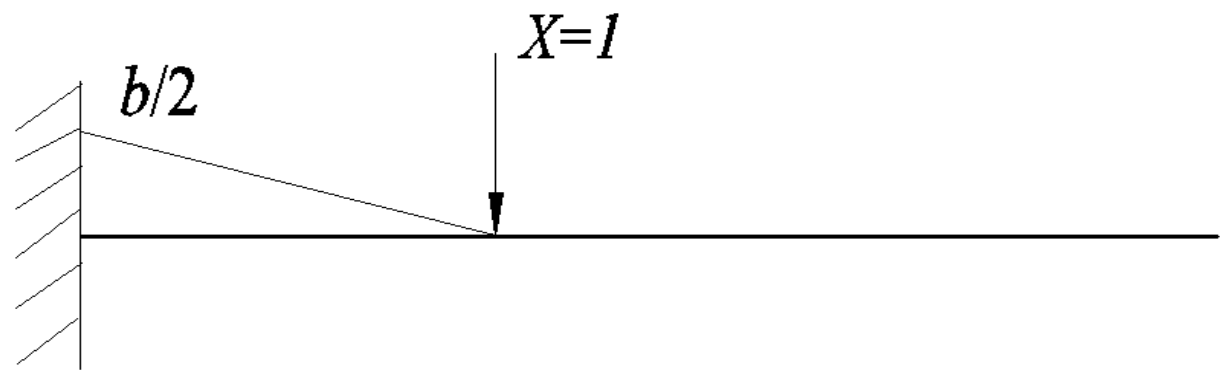

Fig. (7). Bending moment diagram of a virtual force system.

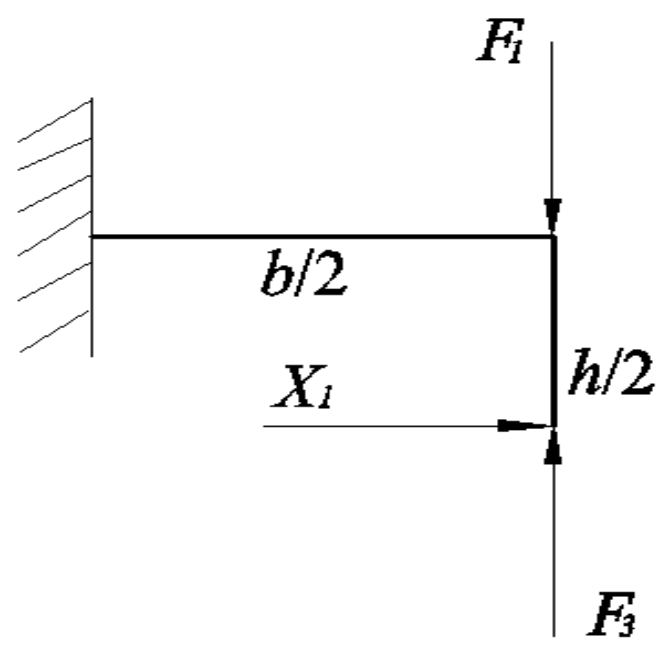

Fig. (8). The simplified quarter structure of box-core.

$\Delta_{\mathrm{F}_{1}}=\Delta_{\mathrm{F}_{1}}^{\prime}$

There is no relative rotation at the interfaces because of the connection using rivet or laser weld. Hence, it can be taken as fix end at the connection point for the top facing plate as shown in Fig. (5) and the corresponding bending moment diagram is shown in Fig. (6).

According to the unit load method, the bending moment diagram under a virtual unit force $(X=1)$ at contact point is presented in Fig. (7).
Then, according to the principle of virtual work, $\Delta \mathrm{F}_{1}$ can be determined:

$$
\Delta_{\mathrm{F}_{1}}=\frac{3 R S b^{2}-R b^{3}-4 F_{1} b^{3}}{96 E I}
$$

where, $E I\left(=t^{3} / 12\right)$ is the flexural stiffness of the facing plate with unit width; $F_{1}$ is the contact force at contact point; $R$ is the shear force, which can be set to unit value $(=1 \mathrm{~N} / \mathrm{mm})$;

Similarly, the box-core can be transformed into the structure in Fig. (8), and the corresponding bending moment dia- 


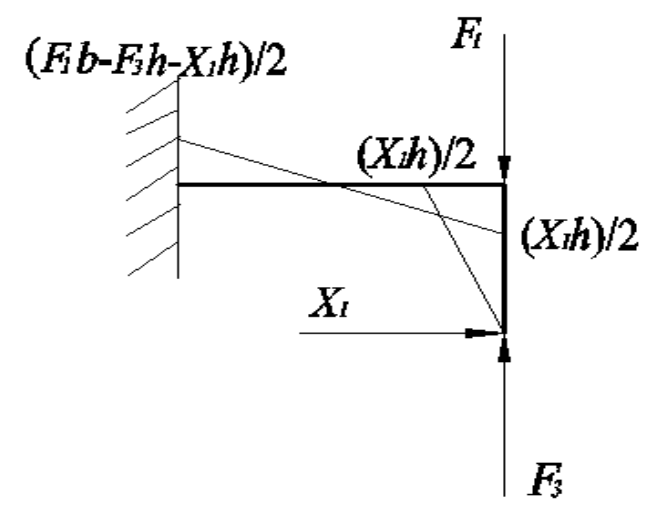

Fig. (9). Bending moment of quarter structure of box-core.

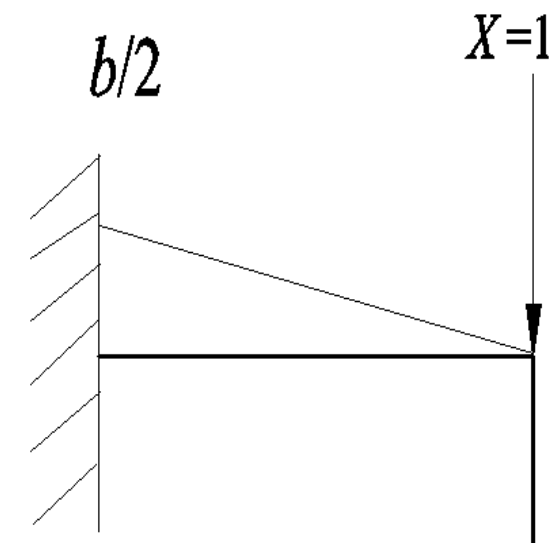

Fig. (10). Bending moment diagram of virtual force system.

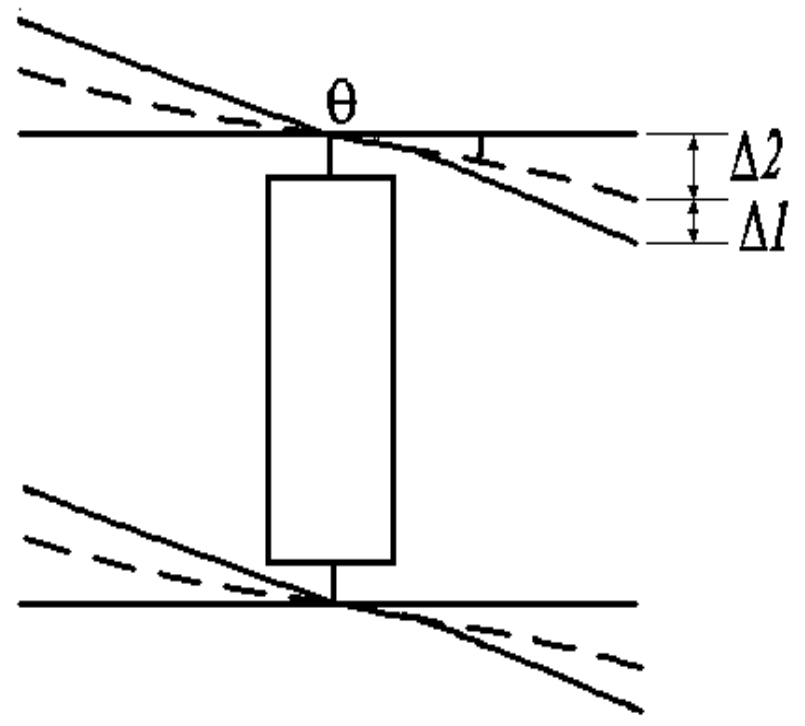

Fig. (11). Figure of relative displacement of a typical segment.

gram is shown in Fig. (9). According to the unit load method, the bending moment diagram under a virtual force $(X=1)$ at contact point is presented in Fig. (10).

Therefore, according to the principle of structural mechanics, $\Delta_{F_{1}}^{\prime}$ can be determined as follow:

$\Delta_{\mathrm{F}_{1}}^{\prime}=\frac{b^{2}\left(2 F_{1} b-2 F_{3} b-3 X_{1} h\right)}{48 E_{c} I_{c}}$ where, $E_{\mathrm{c}} I_{\mathrm{c}}$ is the flexural stiffness of the box-core; $F_{3}$ is axial load; $X_{1}$ is shear force.

Contact forces $F_{1}$ and $F_{2}$ can be obtained from Eqs. (10) (13) based on the assumption that there is no relative displacement between them:

$F_{1}=F_{2}=\frac{3 R S(1+\beta)-R b}{4(1+\beta) b}$ 


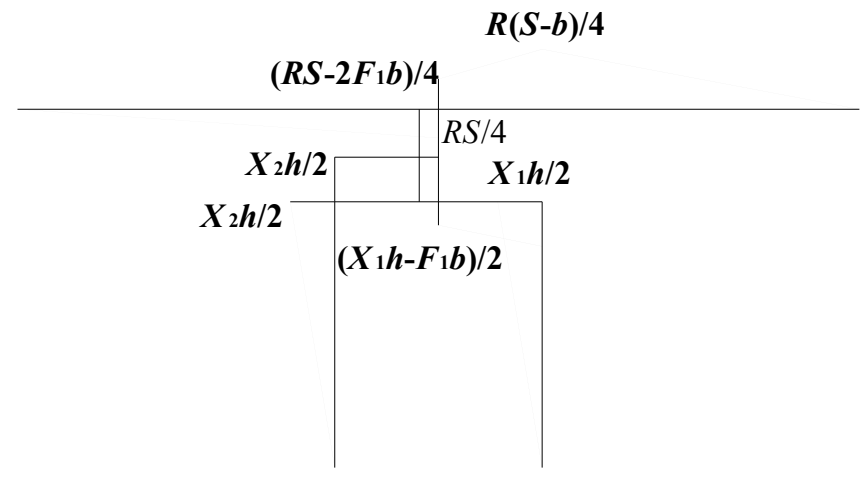

Fig. (12). Bending moment of semi-structure of typical segment.

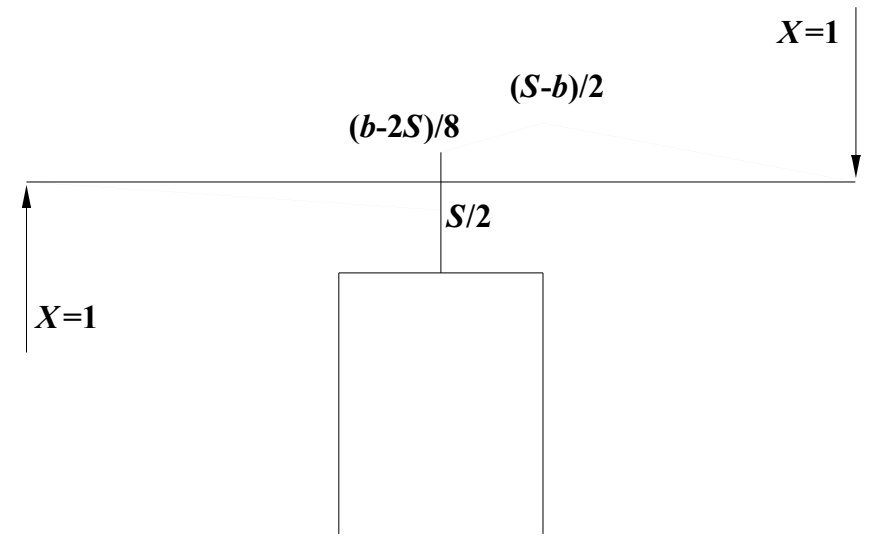

Fig. (13). Bending moment diagram of virtual force system.

where, $\beta=\frac{E_{c} I_{c}}{E I}$ is the ratio of the flexural stiffness of the core stiffener and facing plates;

\section{DEFLECTION AT MID-SPAN OF A SANDWICH BEAM}

The relative displacement at two ends of a typical segment is composed of two types of displacements. One of which is caused by shear forces $\left(\Delta_{1}\right)$ and the other is generated by rotation $(\theta)$ at the connection point $\left(\Delta_{2}\right)$, as shown in Fig. (11). Because the deformation of box-core has no effect on the relative displacement of the typical segment, the deformation of the box-core stiffener is not depicted in Fig. (11).

\section{Relative Shear Displacement of Typical Segment}

The bending moment of the semi-structure of a typical segment is shown in Fig. (12) and the bending moment diagram under a virtual force $(X=1)$ is given in Fig. (13).

From Figs. (12-13), the relative displacement $2 \Delta_{1}$ can be calculated from the following equation

$$
2 \Delta_{1}=\int_{\Gamma} \frac{M}{E I} M_{1} d \Gamma
$$

where, $M$ denotes the bending moment diagram of semistructure of typical segment; $M_{1}$ means the bending moment diagram under virtual force. Hence, the relative displacement can be expressed into the following format:
$2 \Delta_{1}=\left(16 R S^{3}-18 R S^{2} b+9 R S b^{2}-R b^{3}+4 F_{1} b^{3}\right) / 384 E I$

Substitute Eq. (14) into Eq. (16) to produce

$$
2 \Delta_{1}=\frac{16 R S^{3}-18 R S^{2} b+12 R S b^{2}-R b^{3}(2+\beta / 1+\beta)}{384 E I}
$$

\section{Relative rotation displacement of typical segment}

Due to the symmetry of the typical segment, only half of the core stiffener is necessary to be analyzed. Two webs of the core stiffener are taken as one member, of which the flexural stiffness is $2 E_{\mathrm{c}} I_{\mathrm{c}}$. It can be regarded as simple support at the mid-hight of core stiffener, and fixed support at connection point. Because no relative rotation occurs at the interfaces, bending moment of the simplified system with unit rotation in fixed end is shown in Fig. (14).

where, $i=\frac{E I}{L}=\frac{2 E_{c} I_{c}}{h / 2}=\frac{4 E_{c} I_{c}}{h}$

The following moment at fixed end due to rotation is calculated from the following equation:

$M_{1}=3 i=12 E_{c} I_{c} / h$

According to Fig. (12), $M$ can be expressed as follows:

$M=2 \times \frac{X_{1} h}{2}=X_{1} h$ 


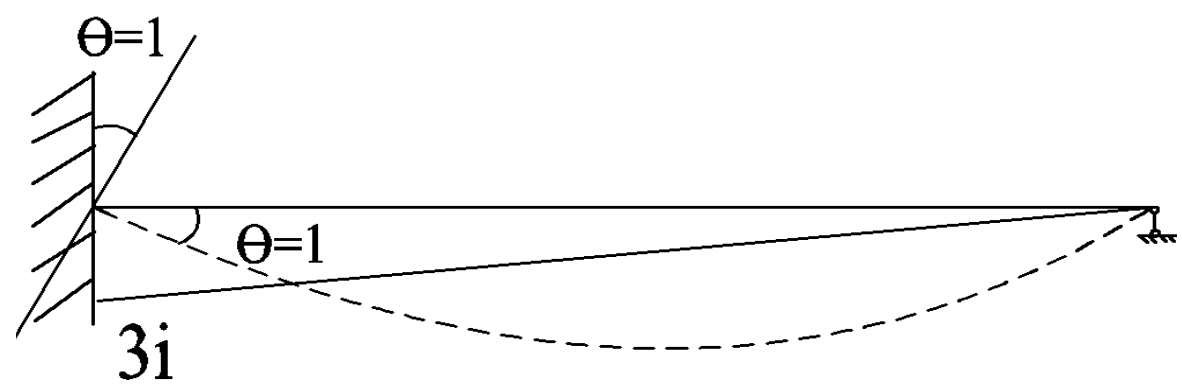

Fig. (14). Bending moment of simplified system.

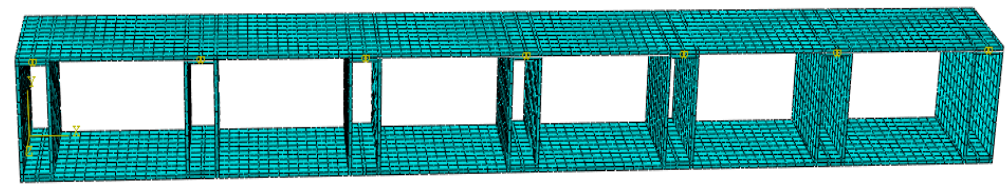

Fig. (15). Mesh of sandwich panel.

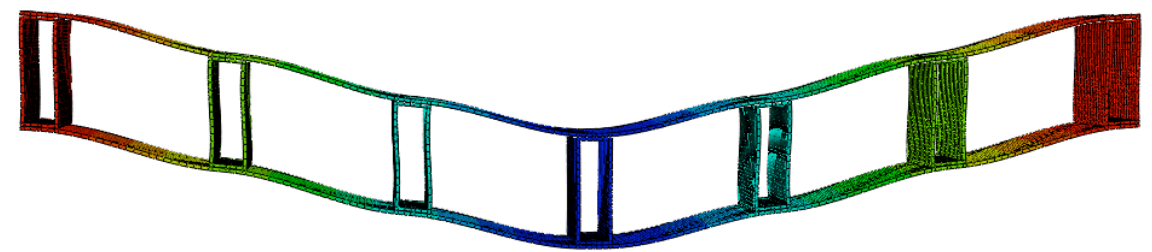

Fig. (16). Deformation of sandwich panel.

From Eqs. (5), (7), (18) and (19), rotation $\theta$ is derived as follow:

$\theta=\frac{R S h}{24 \beta E I}$

Therefore, the relative displacement caused by rotation $\theta$ can be determined:

$2 \Delta_{2}=\theta \cdot S=\frac{R S^{2} h}{24 \beta E I}$

\section{Mid-span Deflection of Sandwich Panel}

Relative displacement of a typical segment is obtained from the following equation:

$$
\begin{aligned}
\Delta & =2 \Delta_{1}+2 \Delta_{2} \\
& =\frac{16 R S^{3}-18 R S^{2} b+12 R S b^{2}-R b^{3}(2+\beta / 1+\beta)}{384 E I}(22) \\
& +\frac{R S^{2} h}{24 \beta E I}
\end{aligned}
$$

As a sandwich panel is consisted of several typical segments, the number of typical segment that is used to calculate deflection of mid-span can be regarded as:

$n=\frac{L / 2}{S}$

where $L$ denotes the length of a sandwich panel.

Hence, deflection at mid-span of a sandwich panel is proposed:

$f=n \Delta$
Because the bending behavior of sandwich panel is in plane strain condition, then flexural stiffness $E I, E_{c} I_{c}$ should be replaced by $E I /\left(1-v^{2}\right), E_{c} I_{c} /\left(1-v^{2}\right)$, respectively. That means, Eq. (24) is revised into the following equation:

$$
f=n \cdot \Delta \cdot\left(1-v^{2}\right)
$$

\section{PARAMETRIC STUDY}

\section{Parameters in Parametric Study}

In the parametric study, four parameters are considered, including the length of flange of a box-core $(b)$, the distance between the centerlines of the top and bottom facing plates $(h)$, the pitch of the box-cores $(S)$, and the thickness of the plates $(t)$. Numerical models of sandwich beam are established by using finite element software ABAQUS. 3D solid element is used to produce the mesh. For the steel material, Young's modulus is 206,000 N/mm and Poisson's ratio is 0.3 . In the finite element analysis, both ends of the sandwich panel are pinned, and a line load of $1 \mathrm{~N} / \mathrm{mm}$ is applied at mid-span. The mesh and the calculated deformation of a typical sandwich panel are shown in Fig. (15) and in Fig. (16), respectively.

From Fig. (16), it can be found that no deformation occurs in the box-core at the mid-span of the sandwich beam. Therefore, the relative displacement caused by rotation in this typical segment should be zero. However, the equation used to calculate the deflection of the sandwich beam at midspan includes the relative rotation displacement. In addition, high stress occurs at the end of the sandwich beam due to the pinned conditions. In this way, the Saint Venant effect can be clearly seen from Fig. (16). Based on the above reasons, 


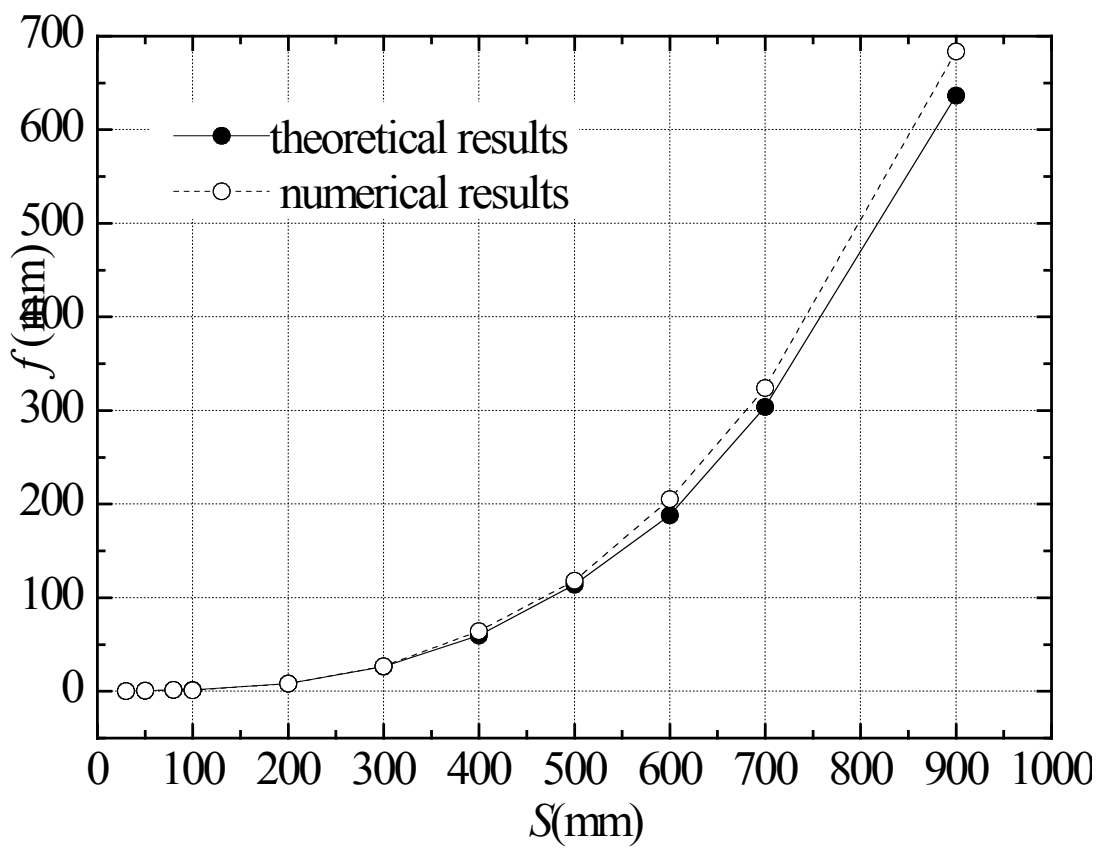

Fig. (17). Deflection- $S$ curves.

Table 1. Details of Sandwich Beam

\begin{tabular}{|c|c|c|c|c|c|c|}
\hline Model & $\begin{array}{c}S \\
(\mathbf{m m})\end{array}$ & $\begin{array}{c}b \\
(\mathbf{m m})\end{array}$ & $\begin{array}{c}h \\
(\mathrm{~mm})\end{array}$ & $\begin{array}{c}t_{1} \\
(\mathrm{~mm})\end{array}$ & $\begin{array}{c}t_{2} \\
(\mathrm{~mm})\end{array}$ & $2 n$ \\
\hline 1 & 30 & 10 & 60 & 2 & 2 & 12 \\
\hline 2 & 50 & 10 & 60 & 2 & 2 & 12 \\
\hline 3 & 80 & 10 & 60 & 2 & 2 & 11 \\
\hline 4 & 100 & 10 & 60 & 2 & 2 & 6 \\
\hline 5 & 200 & 10 & 60 & 2 & 2 & 6 \\
\hline 6 & 300 & 10 & 60 & 2 & 2 & 6 \\
\hline 7 & 400 & 10 & 60 & 2 & 2 & 6 \\
\hline 8 & 500 & 10 & 60 & 2 & 2 & 6 \\
\hline 9 & 600 & 10 & 60 & 2 & 2 & 6 \\
\hline 10 & 700 & 10 & 60 & 2 & 2 & 6 \\
\hline 11 & 900 & 10 & 60 & 2 & 2 & 6 \\
\hline
\end{tabular}

the maximum relative error between theoretical results and numerical results is selected to be $10 \%$. Therefore, if the relative errors in some models are larger than $10 \%$, the deflection of those models can not be calculated accurately by using the equation.

The relative error between theoretical results and numerical results can be obtained by using the following equation:

$\omega=\frac{\left|f_{n}-f_{t}\right|}{f_{n}} \times 100 \%$

Where, the deflection $f_{\mathrm{n}}$ is the numerical results and $f_{\mathrm{t}}$ is the theoretical results.

\section{Effect of $S / b$ on Deflection of Sandwich Beam}

To study the effect of $S$ on the deflection of a sandwich beam, overall 11 finite element models are analyzed. Details of these models are listed in Table 1. It should be noted that the value of $2 n$ in Table 1 is not fixed. As the value of $S$ is small, the deflection of the sandwich beam at mid-span will be also small. Thus, the error between the theoretical and numerical results is relative large. To avoid such error, the number of typical segments is increased when parameter $S$ is small. The results of theoretical and numerical results are given in Table 2. 
Table 2. The Analysis Results at Different Values of $S$

\begin{tabular}{|c|c|c|c|c|c|}
\hline Model & $\begin{array}{c}f_{\mathbf{t}} \\
(\mathbf{m m})\end{array}$ & $\begin{array}{c}\boldsymbol{f}_{\mathbf{n}} \\
(\mathbf{m m})\end{array}$ & $\boldsymbol{S} / \boldsymbol{b}$ & $\boldsymbol{S} / \boldsymbol{h}$ \\
$\mathbf{( \% )}$
\end{tabular}

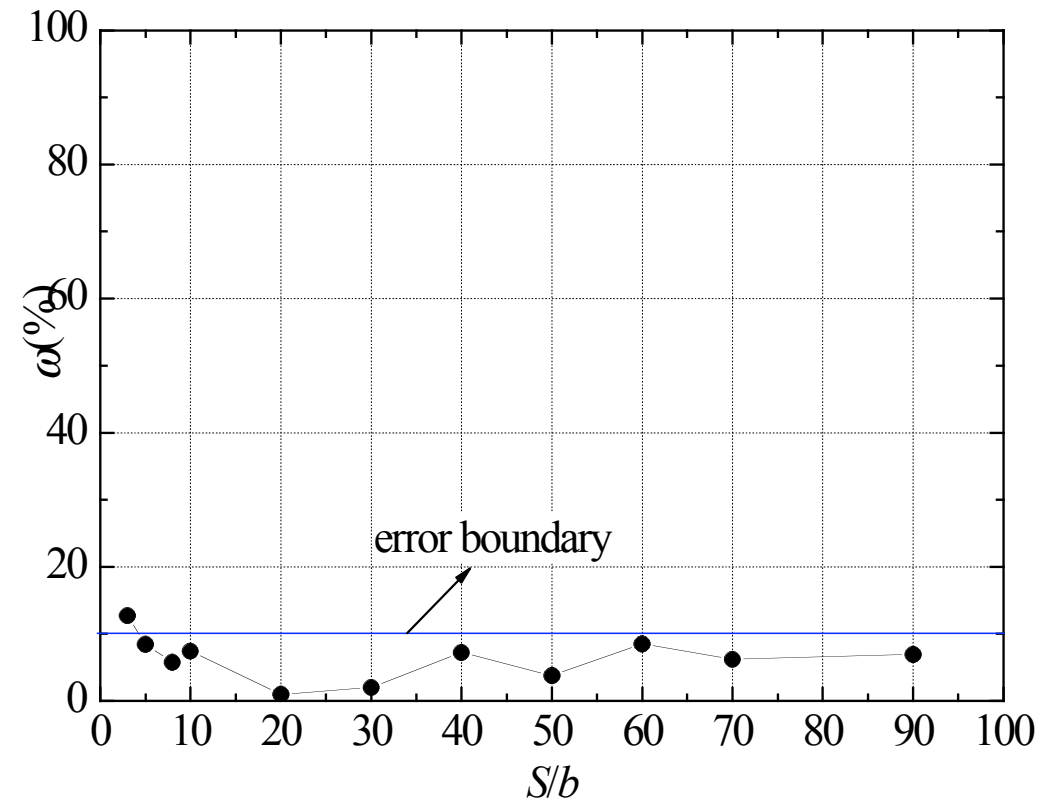

Fig. (18). Error curve of models.

The Deflection- $S$ curves are depicted in Fig. (17) to analyze the results obtained from theoretical equation and numerical simulation in details. The errors in Table 2 are demonstrated in Fig. (18). As can be seen from Figs. (17) (18), the theoretical results and numerical results agree quite well, meaning that the presented equation can estimate the deflection of a sandwich panel accurately enough. It should be noted that the deflection at mid-span increases nonlinearly with increasing the value of $S$. As the pitch of box-cores is large, the relative displacement caused by bending deformation and rotation is considerably increased.

Subsequently, the validity range of the presented equation can be determined directly from Fig. (18). The errors of the numerical models are almost less than $10 \%$ except for model 1 . Therefore, the validity range of the presented equation can be regarded as $S / b \geq 5$.

To study the effect of parameter $b$ on the deflection of a sandwich panel, 7 numerical models are established with the range of $b$ from $2 \mathrm{~mm}$ to $50 \mathrm{~mm}$. All the models are illustrated in Table 3. According to the dimensions of the models, the deflection can be calculated using the theoretical equation. The corresponding results and the numerical results are given in Table 4.

Similarly, all the results can be illustrated in Figs. (1920). As can be found from the figures, the deflection of the sandwich panels can be rarely affected by increasing the value of $b$, especially when it's value exceeds 10 . One 
Table 3. Details of Models with Increasing $b$

\begin{tabular}{|c|c|c|c|c|c|c|}
\hline Model & $\begin{array}{c}\boldsymbol{S} \\
(\mathbf{m m})\end{array}$ & $\begin{array}{c}\boldsymbol{b} \\
(\mathbf{m m})\end{array}$ & $\begin{array}{c}\boldsymbol{h} \\
(\mathbf{m m})\end{array}$ & $\begin{array}{c}\boldsymbol{t}_{\mathbf{1}} \\
(\mathbf{m m})\end{array}$ & $\begin{array}{c}\boldsymbol{t}_{\mathbf{2}} \\
(\mathbf{m m})\end{array}$ & 2 \\
\hline \hline 1 & 200 & 2 & 60 & 2 & 2 & 12 \\
\hline 2 & 200 & 6 & 60 & 2 & 2 & 2 \\
\hline 3 & 200 & 10 & 60 & 2 & 2 & 6 \\
\hline 4 & 200 & 20 & 60 & 2 & 2 & 6 \\
\hline 5 & 200 & 40 & 60 & 2 & 2 \\
\hline 7
\end{tabular}

Table 4. The Analysis Results of Corresponding Models

\begin{tabular}{|c|c|c|c|c|c|}
\hline Model & $\begin{array}{c}f_{\mathrm{t}} \\
(\mathrm{mm})\end{array}$ & $\begin{array}{c}f_{\mathrm{n}} \\
(\mathrm{mm})\end{array}$ & $S / b$ & $h / b$ & $\begin{array}{c}\omega \\
(\%)\end{array}$ \\
\hline 1 & 17.0943 & 20.91 & 100 & 30 & 18.25 \\
\hline 2 & 17.729 & 16.92 & 33.33 & 10 & 4.8 \\
\hline 3 & 8.254 & 8.174 & 20 & 6 & 0.98 \\
\hline 4 & 8.10446 & 8.179 & 10 & 3 & 0.9 \\
\hline 5 & 7.796 & 8.214 & 6.67 & 2 & 5.1 \\
\hline 6 & 7.561 & 8.274 & 5 & 1.5 & 8.6 \\
\hline 7 & 7.3452 & 8.197 & 4 & 1.2 & 10.39 \\
\hline
\end{tabular}

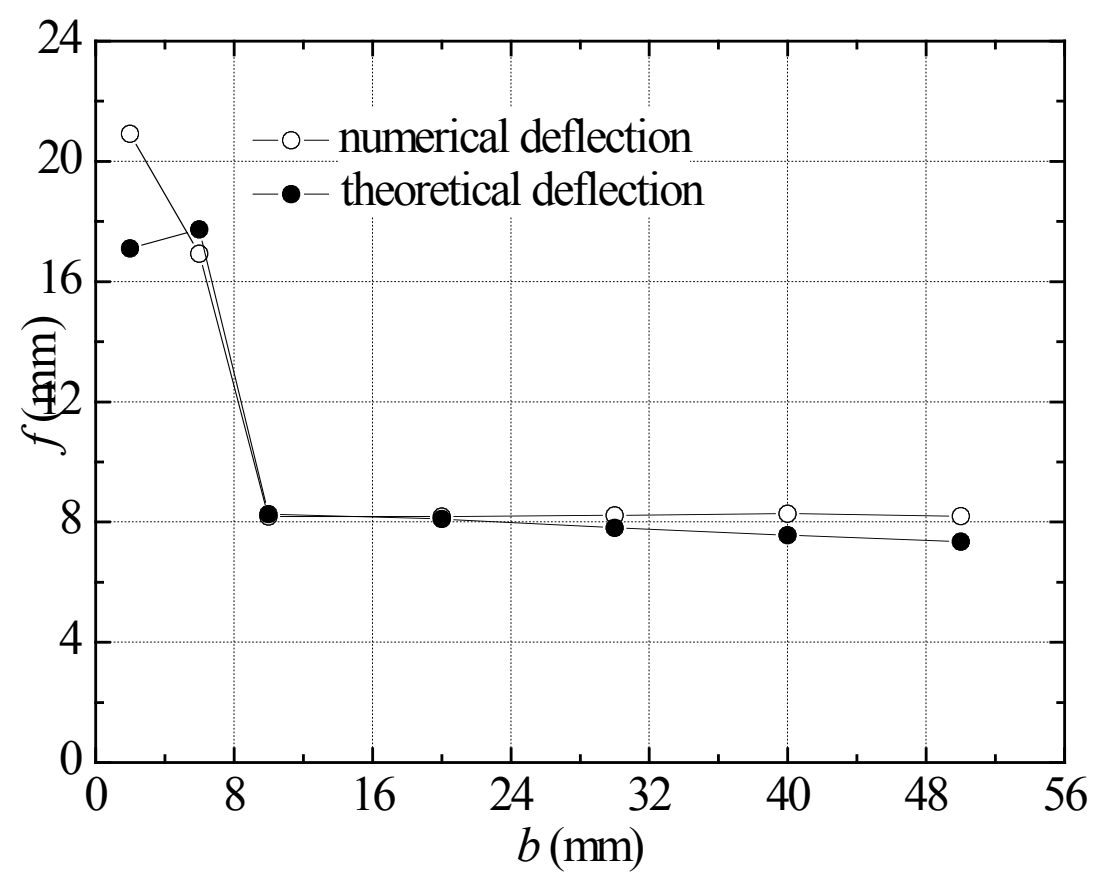

Fig. (19). Deflection- $b$ curves. 


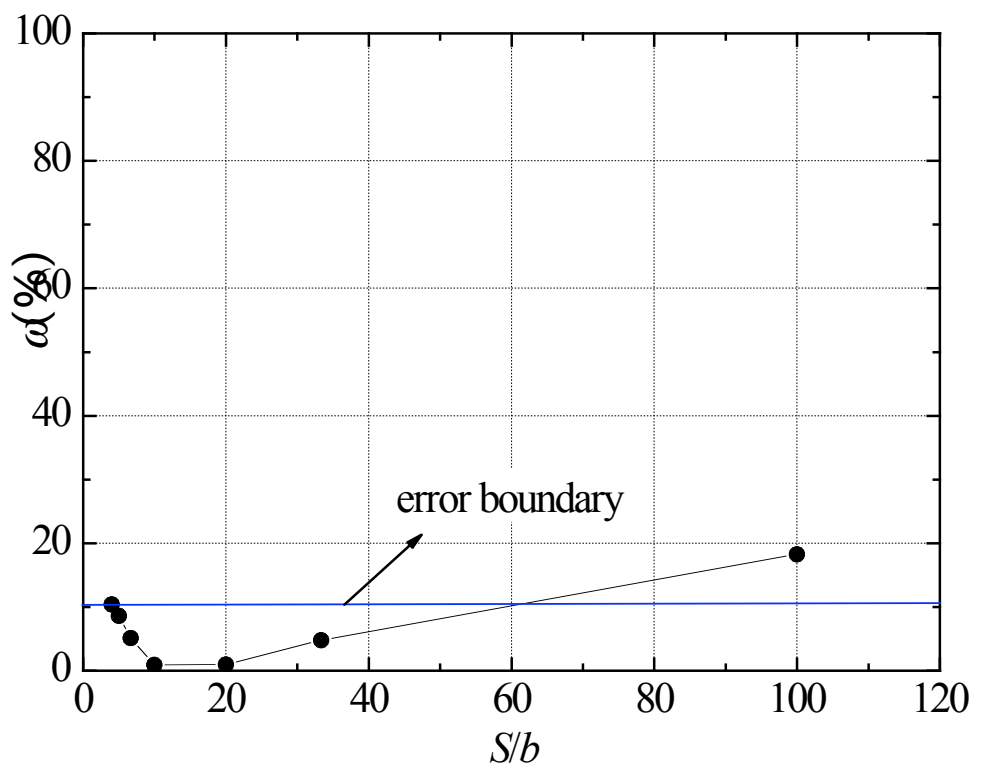

Fig. (20). Error curve of models.

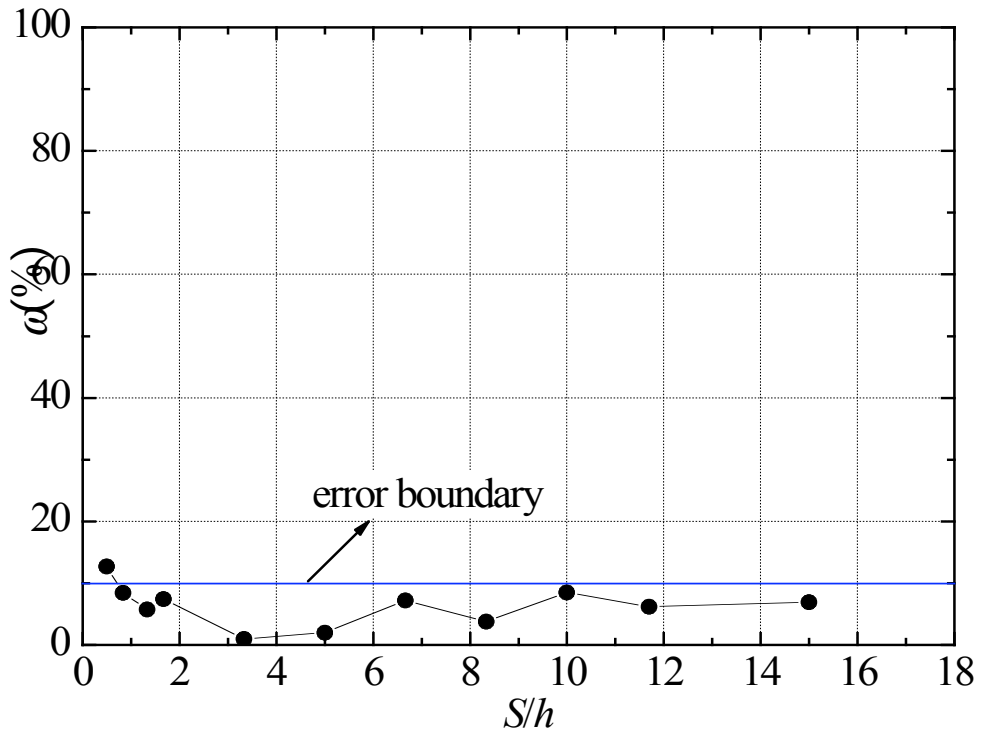

Fig. (21). Error curve of models.

Table 5. Dimensions of Numerical Models

\begin{tabular}{|c|c|c|c|c|c|c|}
\hline Model & $\begin{array}{c}S \\
(\mathrm{~mm})\end{array}$ & $\begin{array}{c}b \\
(\mathrm{~mm})\end{array}$ & $\begin{array}{c}h \\
(\mathrm{~mm})\end{array}$ & $\begin{array}{c}t_{1} \\
(\mathrm{~mm})\end{array}$ & $\begin{array}{c}t_{2} \\
(\mathbf{m m})\end{array}$ & $2 n$ \\
\hline 1 & 200 & 20 & 20 & 2 & 2 & 6 \\
\hline 2 & 200 & 20 & 40 & 2 & 2 & 6 \\
\hline 3 & 200 & 20 & 60 & 2 & 2 & 6 \\
\hline 5 & 200 & 20 & 100 & 2 & 2 & 6 \\
\hline 6 & 200 & 20 & 150 & 2 & 2 & 6 \\
\hline 7 & 200 & 20 & 250 & 2 & 2 & 6 \\
\hline 8 & 200 & 20 & 300 & 2 & 2 & 6 \\
\hline
\end{tabular}


Table 6. The Analysis Results of Models at Different value of $h$

\begin{tabular}{|c|c|c|c|c|c|}
\hline Model & $\begin{array}{c}f_{\mathrm{t}} \\
(\mathrm{mm})\end{array}$ & $\begin{array}{c}f_{\mathrm{n}} \\
(\mathrm{mm})\end{array}$ & $S / h$ & $h / b$ & $\begin{array}{c}\omega \\
(\%)\end{array}$ \\
\hline 1 & 6.5925 & 7.663 & 10 & 1 & 13.97 \\
\hline 2 & 7.2551 & 7.741 & 5 & 2 & 6.3 \\
\hline 3 & 8.10446 & 8.179 & 3.33 & 3 & 0.9 \\
\hline 4 & 8.58 & 8.683 & 2.5 & 4 & 1.2 \\
\hline 5 & 9.243 & 9.193 & 2 & 5 & 0.54 \\
\hline 6 & 10.8995 & 10.47 & 1.333 & 7.5 & 4.1 \\
\hline 7 & 14.213 & 13.02 & 0.8 & 12.2 & 9.2 \\
\hline 8 & 15.8692 & 14.26 & 0.667 & 15 & 11.3 \\
\hline
\end{tabular}

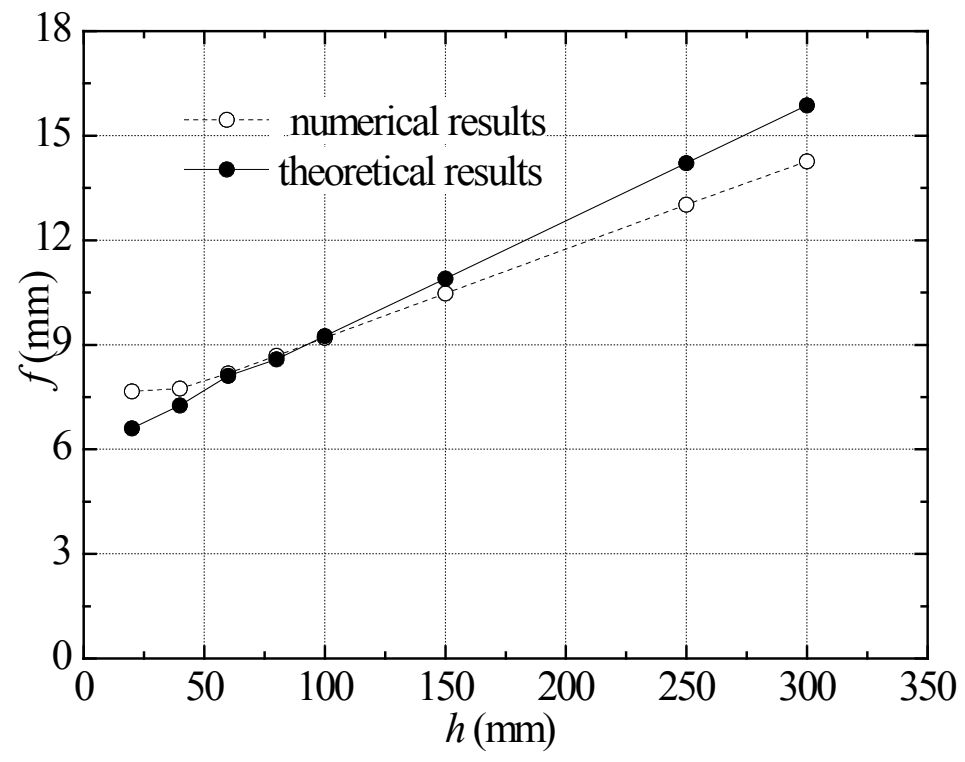

Fig. (22). Deflection- $h$ curves

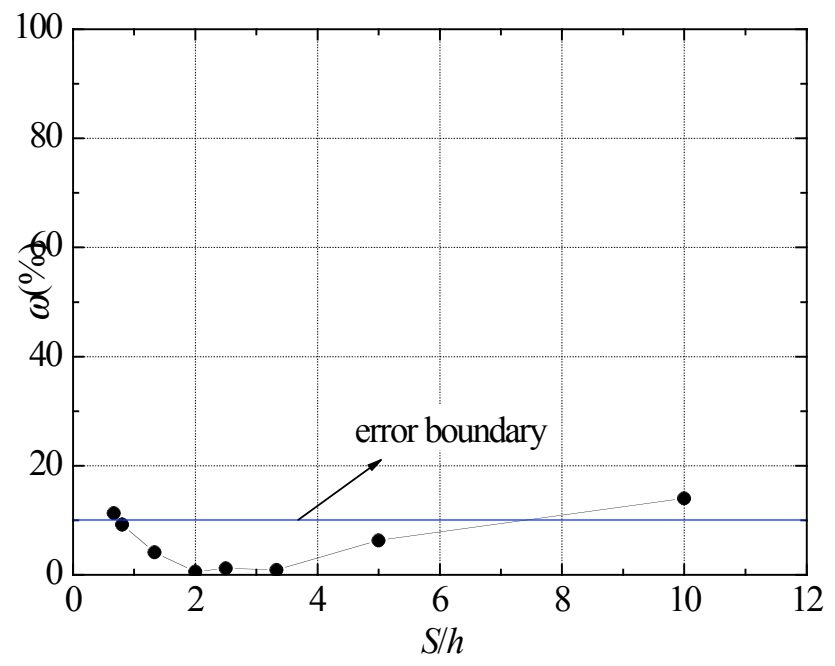

Fig. (23). Error curve of models 
Table 7. Details of Models at Different Values of $t_{1}$ or $t_{2}$

\begin{tabular}{|c|c|c|c|c|c|c|}
\hline Model & $\begin{array}{c}S \\
(\mathbf{m m})\end{array}$ & $\begin{array}{c}b \\
(\mathrm{~mm})\end{array}$ & $\begin{array}{c}h \\
(\mathrm{~mm})\end{array}$ & $\begin{array}{c}t_{1} \\
(\mathrm{~mm})\end{array}$ & $\begin{array}{c}t_{2} \\
(\mathrm{~mm})\end{array}$ & $2 n$ \\
\hline 1 & 200 & 20 & 60 & 2 & 1 & 6 \\
\hline 2 & 200 & 20 & 60 & 2 & 2 & 6 \\
\hline 3 & 200 & 20 & 60 & 2 & 3 & 6 \\
\hline 4 & 200 & 20 & 60 & 2 & 4 & 6 \\
\hline 5 & 200 & 20 & 60 & 2 & 5 & 6 \\
\hline 6 & 200 & 20 & 60 & 2 & 6 & 6 \\
\hline 7 & 200 & 20 & 60 & 2 & 7 & 6 \\
\hline 8 & 200 & 20 & 60 & 2 & 9 & 6 \\
\hline 9 & 200 & 20 & 60 & 1.5 & 9 & 6 \\
\hline 10 & 200 & 20 & 60 & 0.5 & 9 & 6 \\
\hline
\end{tabular}

Table 8. The Corresponding Analysis Results

\begin{tabular}{|c|c|c|c|c|}
\hline Model & $\begin{array}{c}\boldsymbol{f}_{\mathbf{t}} \\
(\mathbf{m m})\end{array}$ & $\begin{array}{c}\boldsymbol{f}_{\mathbf{n}} \\
(\mathbf{m m})\end{array}$ & $\boldsymbol{t}_{\mathbf{2}} / \boldsymbol{t}_{\mathbf{1}}$ & $\begin{array}{c}\boldsymbol{\omega} \\
\mathbf{\%})\end{array}$ \\
\hline \hline 1 & 21.8326 & 20.12 & 0.5 & 8.51 \\
\hline 2 & 7.9177 & 8.179 & 1 & 3.19 \\
\hline 3 & 6.5190 & 6.78 & 2 & 3.85 \\
\hline 4 & 6.1785 & 6.472 & 2.5 & 4.54 \\
\hline 5 & 6.0573 & 6.368 & 3 & 5.11 \\
\hline 6 & 6.0037 & 6.327 & 3.5 & 5.3 \\
\hline 7 & 5.9764 & 6.311 & 4.5 & 6 \\
\hline 10 & 5.9519 & 6.27 & 14.64 & 5.07 \\
\hline
\end{tabular}

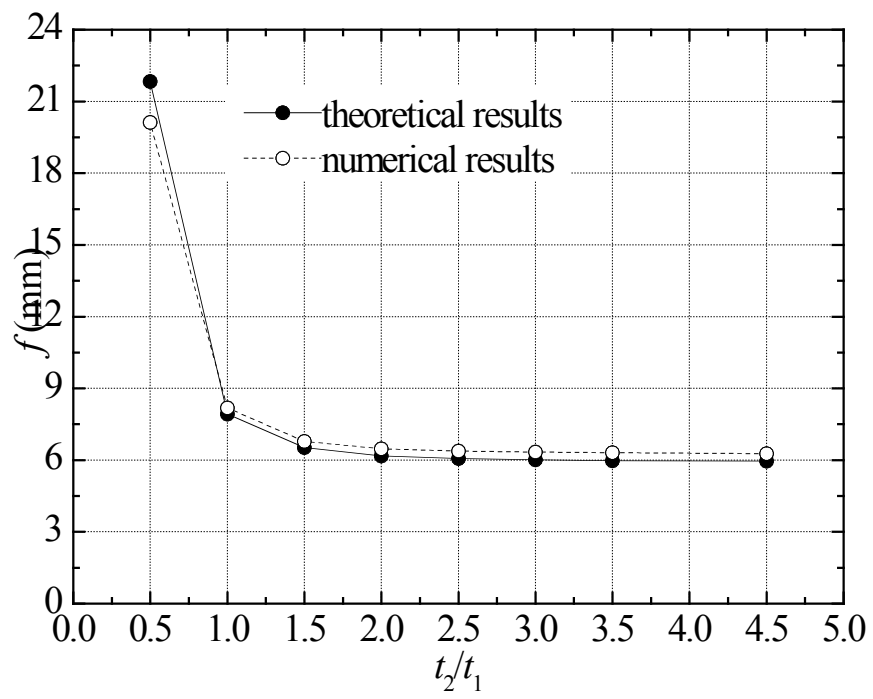

Fig. (24). Deflection curves at different values of $t_{2} / t_{1}$ 


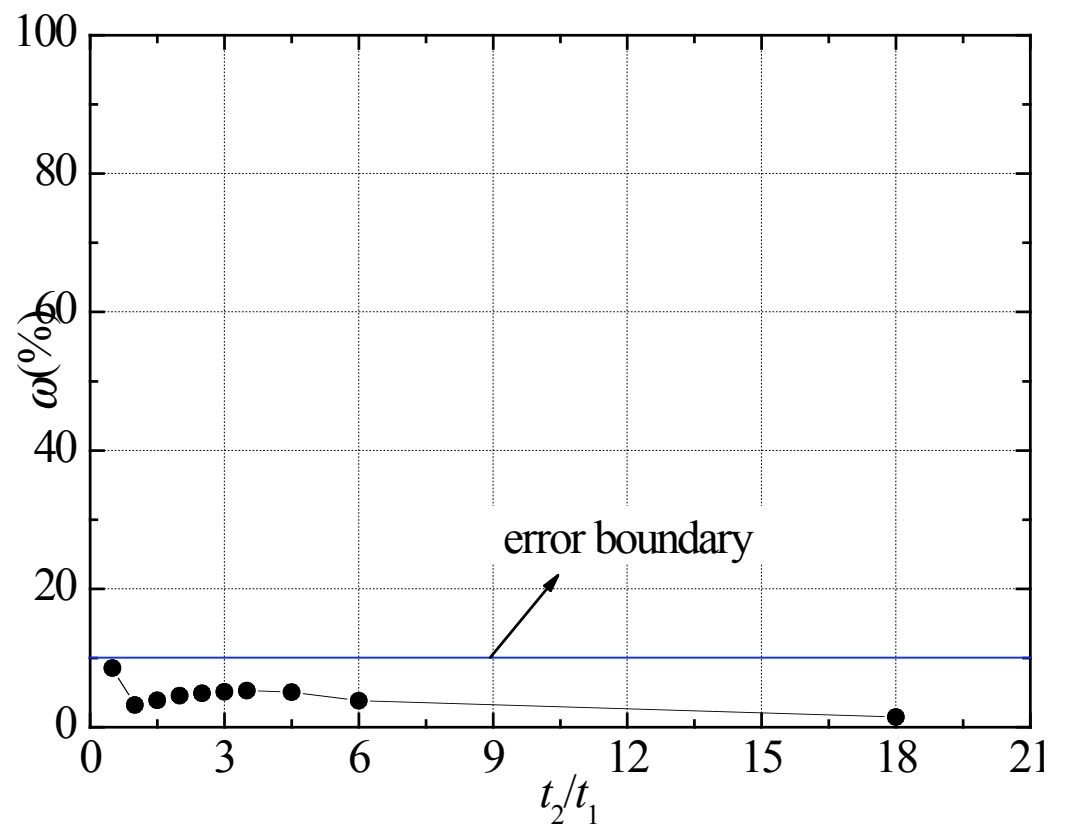

Fig. (25). Error curve of models.

interesting phenomenon is that when the length of flange of a box-core $(b)$ is considerable small, the webs of the box-core can be taken as one member. The deflection of the sandwich panel will be largely increased.

It can be clearly found from Tables $\mathbf{3} \mathbf{4}$ that the errors between the theoretical and numerical results are remarkably small within the range of $10 \leq S / b \leq 90$. Hence, the deflection can be calculated much more accurately using the equation if the sandwich panel is designed in such range.

\section{Effect of $S / h$ on Deflection of Sandwich Beam}

According to Tables 1-2, the error curve of all the numerical models concerning the parameter $S / h$ is shown in Fig. (21). As can be found from this figure, the errors of the models except model 1 do not exceed the error boundary of $10 \%$, indicating that the accuracy of the equation is well verified. Therefore, the validity range of the presented equation is defined as $S / h \geq 0.833$.

The effect of $h$ on the deflection of a sandwich panel is studied through analyzing 8 finite element models. The dimensions of the models are listed in Table 5. Theoretical and numerical results are presented in Table $\mathbf{6}$ and they are also depicted in Figs. (22-23).

From Fig. (22), the relationship between the deflection of sandwich panel at mid-span and the height of box-core is nearly linear. Meanwhile, there is good agreement between the theoretical and numerical results, signifying that the presented equation can estimate the deflection of sandwich panel with high accuracy. It can be seen from Fig. (23), the errors in most of the numerical models are less than $10 \%$, and therefore, the validity range of the presented equation is regarded as $0.8 \leq S / h<10$.

\section{Effect of $h / b$ on Deflection of Sandwich Beam}

As shown in Table 4, some models like model 1 and model 7, their errors between theoretical and numerical re- sults are larger than $10 \%$, while for the other models, they can be analyzed accurately. The validity range of the presented equation can then be determined as: $h / b>1.2$. Meanwhile, the errors of models 3 and 4 , of which the range of $h / b$ is from 3 to 6 , are so small that they can not exceed $1 \%$. That means the equation is able to precisely calculate the deflection of a sandwich panel designed within the validity range.

Similarly, from Table 6 , the validity range of the equation with changing the value of $h$ can be regarded as follow: $1<h / b<9$.

\section{Effect of $t_{2} / t_{1}$ on Deflection of Sandwich Beam}

When studying the bending behavior of the sandwich panel, the parameter $t_{2} / t_{1}$ is of great importance. The models used to analyzed the effect of $t_{2} / t_{1}$ on the deflection of sandwich panels are tabulated in Table 7, and the corresponding analysis results are demonstrated in Table $\mathbf{8}$ and depicted in Figs. (24-25).

The analysis results indicate that the deflection of a sandwich panel is rarely influenced by increasing the value of $t_{2}$ when the value of $t_{2} / t_{1}$ exceeds 2.0. It can be clearly found that the deflection of model 1 is much larger than that of the other models in Fig. (24). The main reason is that the thickness of box-core is too small, causing that the flexural stiffness of the box-core stiffener is also small. Therefore, the deformation of box-core will be much larger than that of the facing plates (as shown in Fig. 26).

As can be seen from Fig. (25), the errors of all the models are less than $10 \%$, predicting that the deflection of sandwich panel can be well estimated. Thus, the corresponding validity range of the equation is defined as $t_{2} / t_{1} \geq 0.5$.

To further verify the accuracy of the validity range of the above presented equation, overall 15 finite element models are analyzed. Details of these models are given in Table 9. The theoretical and numerical results of all the models are demonstrated in Table 10. From the listed results in Table 


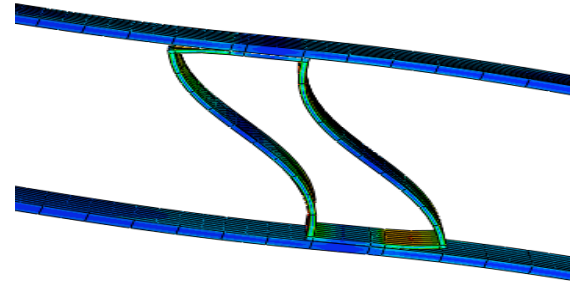

Fig. (26). The deformation of model $1\left(t_{1}=2 \mathrm{~mm}, t_{2}=1 \mathrm{~mm}\right)$.

Table 9. Dimensions of Sandwich Panel Models

\begin{tabular}{|c|c|c|c|c|c|c|}
\hline Model & $\begin{array}{c}S \\
(\mathbf{m m})\end{array}$ & $\begin{array}{c}b \\
(\mathbf{m m})\end{array}$ & $\begin{array}{c}h \\
(\mathrm{~mm})\end{array}$ & $\begin{array}{c}t_{1} \\
(\mathrm{~mm})\end{array}$ & $\begin{array}{c}t_{2} \\
(\mathrm{~mm})\end{array}$ & $2 n$ \\
\hline 1 & 60 & 20 & 60 & 2 & 2 & 11 \\
\hline 2 & 100 & 20 & 60 & 2 & 2 & 6 \\
\hline 3 & 150 & 25 & 70 & 2 & 3 & 8 \\
\hline 4 & 200 & 20 & 60 & 2 & 2 & 6 \\
\hline 5 & 200 & 30 & 80 & 2 & 2 & 8 \\
\hline 6 & 300 & 20 & 60 & 2 & 2 & 6 \\
\hline 7 & 300 & 30 & 50 & 2 & 4 & 8 \\
\hline 8 & 300 & 30 & 100 & 2 & 5 & 8 \\
\hline 9 & 350 & 15 & 45 & 2 & 6 & 8 \\
\hline 10 & 400 & 20 & 60 & 2 & 2 & 6 \\
\hline 11 & 400 & 40 & 80 & 2 & 2 & 8 \\
\hline 12 & 450 & 50 & 60 & 2 & 2 & 8 \\
\hline 13 & 500 & 20 & 60 & 2 & 2 & 6 \\
\hline 14 & 500 & 10 & 100 & 2 & 2 & 8 \\
\hline 15 & 600 & 8 & 80 & 2 & 2 & 8 \\
\hline
\end{tabular}

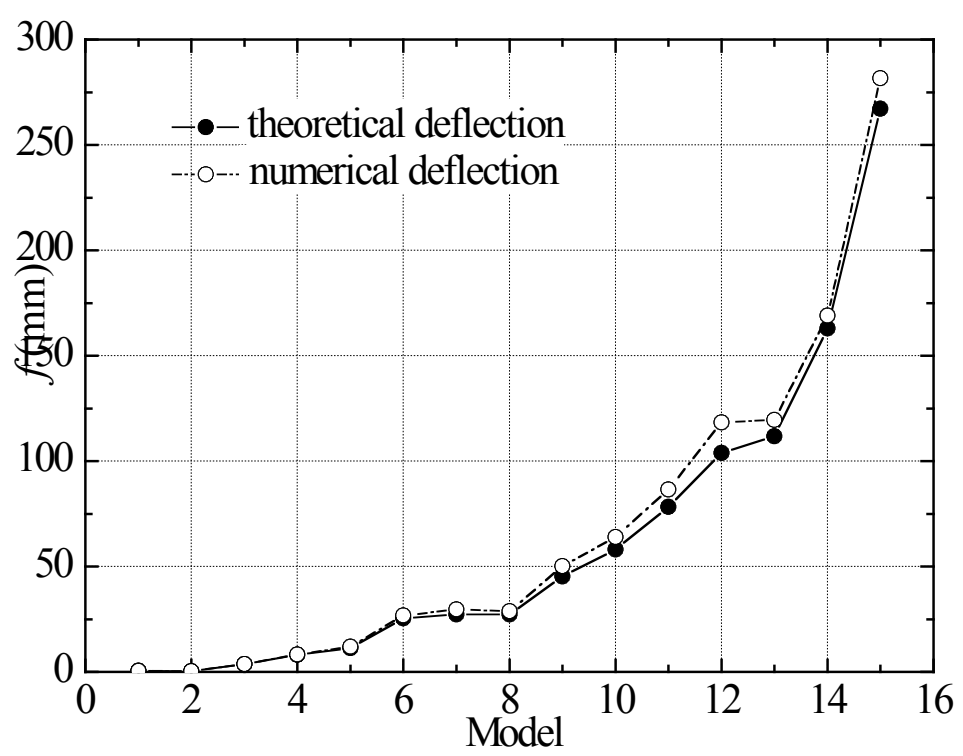

Fig. (27). Deflection curve of numerical and theoretical

10, the deflection curves of numerical and theoretical results are shown in Fig. (27) and the relative error curve is presented in Fig. (28).
From Fig. (27) and Fig. (28), it is found that the numerical and theoretical results agree well, and the values of error are within $10 \%$, except model 12 . The reason why the error 
Table 10.Numerical and Theoretical Results of Sandwich Panel

\begin{tabular}{|c|c|c|c|}
\hline Model & $\begin{array}{c}f_{\mathrm{t}} \\
(\mathrm{mm})\end{array}$ & $\begin{array}{c}f_{\mathrm{n}} \\
(\mathrm{mm})\end{array}$ & $\begin{array}{c}\omega \\
(\%)\end{array}$ \\
\hline 1 & 0.576 & 0.586 & 1.71 \\
\hline 2 & 0.406 & 0.393 & 3.31 \\
\hline 3 & 3.697 & 3.736 & 1.04 \\
\hline 4 & 8.104 & 8.179 & 0.92 \\
\hline 5 & 11.231 & 11.87 & 5.38 \\
\hline 6 & 25.382 & 26.69 & 4.90 \\
\hline 7 & 27.306 & 29.62 & 7.81 \\
\hline 8 & 27.321 & 28.85 & 5.30 \\
\hline 9 & 45.357 & 50.15 & 9.56 \\
\hline 10 & 58.078 & 64.02 & 9.28 \\
\hline 11 & 78.355 & 86.51 & 9.43 \\
\hline 12 & 103.8 & 118.3 & 12.26 \\
\hline 13 & 111.84 & 119.5 & 6.41 \\
\hline 14 & 162.997 & 169 & 3.55 \\
\hline 15 & 267.25 & 281.7 & 5.13 \\
\hline
\end{tabular}

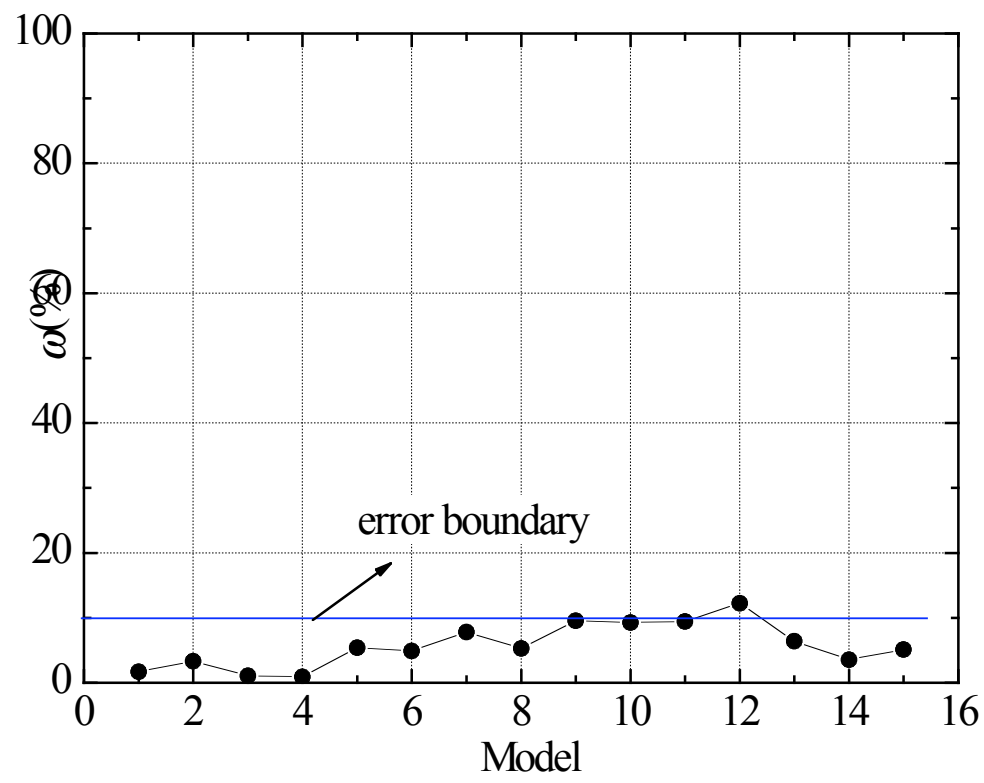

Fig. (28). Error curve of models.

of model 12 is bigger than $10 \%$ may be related to the assumptions used in deriving the equations. According to the validity range of the equation, the parameter $h / b$ in model 12 is equal to 1.2 , which is not included in the validity range.

\section{CONCLUSIONS}

In this paper, the deflection at mid-span in the weak direction for a box-core sandwich panel is derived. To analyze the bending behavior of a sandwich panel, typical segment is separated with the compatibility conditions and contact forces are considered to present the real bending behavior. The deflection at mid-span of a sandwich panel is obtained by the principle of virtual work. Subsequently, the valid region of the presented equation is studied through parametric study. To further verify the accuracy of the equation, finite element models are analyzed. The errors between numerical and theoretical results are within $10 \%$ if the geometrical parameters are within a validity range. 


\section{CONFLICT OF INTEREST}

The authors confirm that this article content has no conflicts of interest.

\section{ACKNOWLEDGEMENTS}

Declared none.

\section{REFERENCES}

[1] F.Q. Ye and G.P. Zhao, Numerical simulation of lattice metal sandwich plates in the energy absorption characteristics under impact loading, Proceedings of Chinese Society of Theoretical and Applied Mechanics, 2009.

[2] R.X. Bai, H.R. Chen and C.J. Su. Buckling finite element analysis of laminate composite sandwich panel plates considering shear effect of the faces and the core. Fiber Reinforced Plastic/Composites, vol. 5, pp. 3-6, 1999.
[3] J. Xie, L.M. Zhu and Z.Q. Dai, "Sandwich plate theory and finite element analysis of concrete sandwich two-way panels," J. China Civil Eng., vol. 38, no. 7, pp. 39-44, 2005.

[4] C. Libove and R.E. Hubka, "Elastic constants for corrugated-core sandwich plates," J. NACA Tech., Note 2289, vol. 8, pp. 1-106, 1951.

[5] L.K. William, "Elastic constants for superplastically formed/diffusion-bonded corrugated sandwich core," NASA Technical Paper, pp. 1-79, 1980.

[6] T.C. Fung, K.H. Tan and T.S. Lok, "Shear stiffness $D_{Q y}$ for C-core sandwich panels," J. Struc. Eng., vol. 122, no. 8, pp. 958-966, 1996.

[7] T.C. Fung and K.H. Tan, "Shear stiffness for Z-core sandwich panels," J. Struc. Eng., vol. 124, no. 7, pp. 809-816, 1998

[8] Z.G. Wang, J. Shan and D.P. He, "Dynamic response analysis of sandwich plates with pyramidal truss cores," J. Chinese Quart. Mech., vol. 27, no. 4, pp. 707-713, 2006.

[9] H.Y. Wang and D.Y. Zhao, "Finite element analysis for sandwich plates with moderately thick viscoelastic cores," J. Ship Mech., vol. 13 , no. 5, pp. 795-802, 2009.

Received: September 08, 2013

Revised: October 06, 2013

Accepted: October 10, 2013

(C) CUI Mingjuan; Licensee Bentham Open.

This is an open access article licensed under the terms of the Creative Commons Attribution Non-Commercial License (http://creativecommons.org/licenses/by-nc/3.0/) which permits unrestricted, non-commercial use, distribution and reproduction in any medium, provided the work is properly cited. 